\title{
Porcionamento, adequação energética e controle do desperdício em uma creche
}

\section{Serving size, energetic adequacy and waste control in a nursery school}

Jamille Caroso Andrade

Flávia Milagres Campos'

1 Núcleo de Nutrição, Centro de Ciências Biológicas e da Saúde. Universidade Federal de Sergipe. Cidade Universitária Prof. José Aloísio de Campos - Av. Marechal Rondon, s/n $\mathrm{n}^{0}$ Jardim Rosa Elze. 49100-100 - São Cristóvão, SE, Brasil.

Correspondência / Correspondence

Flávia Milagres Campos

E-mail: flaviamilagresı@gmail.com

\section{Resumo}

Objetivo: Descrever o processo de padronização do porcionamento de refeições oferecidas a crianças de uma creche, para adequação da oferta energética e controle do desperdício. Métodos: Foram avaliados restos e sobras de alimentos do almoço, lanche e jantar, durante 11 dias, de uma creche em Aracaju-SE, que atende a 45 crianças entre oito meses e dois anos. Após os primeiros sete dias, implementou-se a padronização do porcionamento. Para tanto, realizou-se treinamento com trabalhadoras empregando quadros com foto e descrição da medida caseira das preparações. O tamanho das porções foi determinado considerando-se a recomendação energética para a faixa etária. Para padronização das medidas caseiras, foram empregados utensílios usados na creche. Após esta etapa, foram novamente coletados dados de restos e sobras de alimentos durante quatro dias. Resultados: Os percentuais médios de resto-ingestão, na primeira etapa, foram de $21 \%$ no lanche, $33 \%$ no almoço e $36 \%$ no jantar. Após a padronização do porcionamento, tais percentuais caíram para $14 \%$ no lanche, $16 \%$ no almoço e $15 \%$ no jantar. A adequação do valor calórico diário foi avaliada em três dias e variou de 63 a 106\%. Os resultados demonstram clara importância da padronização do porcionamento para controle do desperdício e adequação da oferta energética em estabelecimentos produtores de refeições.

Palavras-chave: Alimentação institucional. Creche. Desperdício de alimento. Produção de alimento. 


\section{Abstract}

Objective: Describe the serving size standardization process of meals offered to children in a nursery school, for adequacy of energetic offer and waste control. Methods: During 11 days in a nursery school in Aracaju, state of Sergipe, Brazil, attending 45 children between eight months and two years old, were evaluated the rest and food scrap from lunch, snack and dinner. After the first seven days, the serving sizes standardization was implemented. In order to do it, training was conducted with the employees, based on pictures and descriptions of homemade measures preparation. The serving size was determined by considering energy recommendation for children. Utensils used in the nursery school were used for standardization of homemade measures. After this stage, data of the rest and the food scrap was collected again for four days. Results: The average percentages of rest-intake, on first stage, were $21 \%$ on snack, $33 \%$ on lunch and $36 \%$ on dinner. After standardization of serving sizes, these percentages dropped to $14 \%$ on snack, $16 \%$ on lunch and $15 \%$ on dinner. The adequacy of daily energy was evaluated for three days and ranged from 63 to $106 \%$. The results clearly show the importance of standardization of serving portion sizes to control waste and adequacy of energetic offer in food producing establishments.

Key words: Institutional feeding, child day care center, food wastefulness, food production.

\section{Introdução}

A alimentação infantil é algo peculiar, uma vez que a partir dela os hábitos alimentares serão construídos durante as demais fases da vida. A alimentação de crianças menores de dois anos de idade possui algumas particularidades, porque é nessa faixa etária que ocorre a introdução da alimentação complementar.

A partir de seis meses de idade, parte da energia oferecida à criança deve ser proveniente dos alimentos complementares ao leite materno. Essa oferta deve ser realizada de forma gradual, com alterações na consistência até que a alimentação da criança se iguale à alimentação da família. ${ }^{1}$ De acordo com a Organização Mundial da Saúde, ${ }^{2}$ a frequência com que os alimentos complementares devem ser oferecidos às crianças pequenas varia de acordo com a densidade energética dos alimentos da dieta. 
Há algumas décadas, o desenvolvimento infantil acontecia, quase exclusivamente, em ambiente doméstico. Entretanto, a partir da década de 1970 no Brasil, a expansão da economia, o processo de urbanização e a crescente industrialização favoreceram a incorporação de novos trabalhadores no mercado. Isso abriu espaço para maior inserção da mulher no mercado de trabalho ${ }^{3}$ e, somado a outras transformações econômicas, sociais e demográficas, contribuiu para o surgimento e crescimento das creches. Hoje, as creches têm o papel de educar e alimentar as crianças de mães que, geralmente, trabalham fora de casa. ${ }^{4}$

A creche exerce vários papéis importantes relacionados ao desenvolvimento da criança, quer seja esse físico, psíquico ou social. A importância da creche também se relaciona à qualidade da alimentação oferecida, uma vez que práticas alimentares inadequadas ou deficiências nutricionais podem causar grandes prejuízos à saúde da criança. Além do aspecto nutricional, extremamente importante para o crescimento da criança, a alimentação apresenta aspectos afetivos, culturais e sociais que não podem ser desprezados. As creches se inserem na questão da educação alimentar e nutricional, especialmente quanto à aceitação, pela criança, de alimentos variados, o que pode influenciar futuras práticas e comportamentos alimentares. A educação alimentar e nutricional, nesse âmbito, deve ser direcionada sobretudo aos responsáveis pela alimentação no local (cozinheiros, copeiras), que irão distribuir e preparar as refeições.

A oferta de refeições nutricionalmente adequadas em creches e pré-escolas é de fundamental importância. Contudo, além do ponto de vista nutricional, que valoriza a variedade, o equilíbrio e a moderação, a alimentação envolve outros aspectos, como o prazer, o sabor, as dimensões de gênero e etnia, a produção ambientalmente sustentável e livre de contaminantes químicos, físicos e biológicos, igualmente importantes. ${ }^{5,6}$ O planejamento do cardápio deve ser feito, portanto, para atender a todas estas questões da melhor maneira possível.

Entretanto, o planejamento do cardápio é uma das etapas para a oferta de refeições adequadas. É necessário, ainda, ajustar a produção e distribuição das refeições. Em levantamento sobre consumo, realizado em 16 berçários na cidade de São Paulo por meio de pesagem direta, identificou-se déficit energético, apesar de os cardápios serem elaborados por nutricionistas. ${ }^{7}$ Isso reforça a importância do acompanhamento da produção e da distribuição das preparações servidas durante as refeições. Destaca-se também a importância do acompanhamento da ingestão, das sobras e restos das refeições. São diversos os fatores que influenciam a ingestão de alimentos, como a relação da criança com o ambiente e as pessoas envolvidas com a oferta da refeição e as condições no momento da refeição. Assim, para atender às recomendações nutricionais e visando facilitar e agilizar a distribuição das refeições, pode ser empregada a padronização de medidas caseiras para o porcionamento das refeições.

Segundo Vargas ${ }^{8}$ "[...] medidas caseiras são instrumentos destinados a medir as quantidades de determinados alimentos que serão utilizados para preparar e servir refeições, aferidas por meio de 
utensílios existentes em qualquer residência, como copos, xícaras, colheres, conchas, etc. Devido a sua facilidade de uso e acesso, esses instrumentos culinários são amplamente utilizados tanto em cozinhas residenciais quanto em Unidades de Alimentação e Nutrição (UAN), para calcular as quantidades de alimentos que serão preparadas nas refeições."

A implantação de medidas caseiras padronizadas depende da sensibilização em relação à importância da padronização e a capacitação dos trabalhadores em relação às quantidades ofertadas. Por isso, faz-se necessário um trabalho de educação alimentar e nutricional com os trabalhadores responsáveis pelo porcionamento das refeições, baseado em uma relação dialógica entre os atores de aprendizagem. ${ }^{9}$

A padronização, além de auxiliar o preparo das refeições e favorecer a adequação da oferta energética, atua ainda como fator para redução do desperdício alimentar, uma vez que as quantidades padronizadas evitam o excesso de alimentos no prato, excesso de alimentos preparados e consequentemente, minimiza o descarte. Na questão do gerenciamento de resíduos sólidos, que se coloca inclusive legalmente, ${ }^{10}$ a não-geração, como o controle das sobras de produção e restos alimentares, tem prioridade sobre as demais ações. Além disso, a padronização pode levar à diminuição do desperdício, com consequente redução dos custos e da geração de impactos ambientais, e está alinhada com a consolidação do direito humano à alimentação adequada e promoção da segurança alimentar e nutricional.

Dada a escassez de estudos relacionados ao porcionamento e avaliação do desperdício em creches, este estudo teve como objetivo descrever o processo de padronização do porcionamento de refeições oferecidas em uma creche, com a avaliação de restos e sobras, para adequação da oferta de alimentos e controle do desperdício.

\section{Métodos}

\section{Espaço da pesquisa}

A creche em que foi desenvolvido o estudo pertence a uma instituição paraestatal, sem fins lucrativos. Está situada no bairro Siqueira Campos, zona oeste da cidade de Aracaju, e 25 pessoas lá prestam serviços, dentre as quais professores, auxiliares de limpeza, cozinheira, auxiliar de cozinha e estagiários. Oferece 45 vagas para crianças de oito a 24 meses e funciona de segunda a sexta, das $7 \mathrm{~h} 10 \mathrm{~min}$ às $17 \mathrm{~h} 30 \mathrm{~min}$. As vagas são destinadas a crianças de pais empregados no setor comercial, e para que elas usufruam da creche é requerido o pagamento de uma taxa mensal. Um dos fatores que levam à grande procura pelos serviços da creche é a oferta do serviço a preços bastante acessíveis. À época do estudo, todas as vagas estavam ocupadas. 
Durante o período em que permanecem na creche, as crianças realizam as seguintes refeições: lanche da manhã às $9 \mathrm{~h}$, almoço às $11 \mathrm{~h}$, lanche da tarde às $14 \mathrm{~h}$ e jantar às $16 \mathrm{~h}$. O lanche da manhã é encaminhado de casa pelos pais, cabendo à creche a oferta das outras três refeições. O setor de produção onde é realizado todo o preparo das refeições conta com duas trabalhadoras (cozinheira e ajudante de cozinha). As refeições são servidas e oferecidas às crianças pelas professoras e assistentes responsáveis por cada turma.

\section{Recomendação energética}

A recomendação energética empregada, a fim de adequar o tamanho das porções dos alimentos oferecidos pela instituição, foi baseada na Recommended Dietary Alowance, ${ }^{11,12}$ conforme orientação do Ministério da Saúde. ${ }^{1}$

As crianças são divididas em duas turmas: crianças de oito meses a um ano e cinco meses de idade (turma 1) e crianças de um ano e seis meses a dois anos (turma 2). A recomendação energética foi calculada para cada turma, utilizando-se a média dos pesos das crianças na turma 1 e na turma 2. Os dados dos pesos foram disponibilizados pela creche, uma vez que é realizada avaliação antropométrica das crianças duas vezes por semestre.

\section{Padronização da porção e medida caseira}

Estimado o tamanho das porções a serem oferecidas às crianças com base na recomendação energética. Embora a creche envolvida no presente trabalho não esteja vinculada ao Programa Nacional de Alimentação Escolar (PNAE), foi utilizada, com adaptações, a recomendação do programa para oferta de no mínimo $70 \%$ das necessidades diárias das crianças, quando em período integral. ${ }^{13}$ Contudo, apesar de as crianças permanecerem na creche em tempo integral, realizam apenas três refeições, dentre elas, duas principais (almoço e jantar). Por isso, optou-se por empregar $60 \%$ da recomendação energética diária para estimar as porções. Sendo assim, a distribuição do valor energético total foi de $25 \%$ a $30 \%$ para almoço, $10 \%$ a $15 \%$ para lanche e $20 \%$ a $25 \%$ para jantar. Os demais $40 \%$ da necessidade de energia diária são ofertados no desjejum e ceia (realizados em casa) e lanche da manhã (realizada na creche, com alimentos encaminhados pelos pais). A creche optou por não elaborar o lanche da manhã, uma vez que não havia tempo hábil suficiente, dado o horário de trabalho das duas envolvidas na produção das refeições. Como as crianças têm entre oito e 24 meses, de segunda a sexta, em geral, recebem as refeições lácteas em casa e a alimentação complementar na creche. 
Para a padronização das medidas caseiras, foi realizado o cálculo do valor energético do cardápio de três dias não consecutivos. Para tanto, foi feito o acompanhamento do preparo dos alimentos, a pesagem de cada ingrediente e empregada a Tabela Brasileira de Composição dos Alimentos (NEPA-UNICAMP). ${ }^{14} \mathrm{O}$ tamanho das porções foi definido com base no valor energético da preparação, considerando a faixa etária a que se destinava. As medidas caseiras foram, então, estabelecidas a partir do tamanho da porção e consistência das preparações. Foram utilizados utensílios comumente empregados na creche para o porcionamento das refeições e para pesagem utilizou-se balança eletrônica da marca Plenna, com capacidade de $2 \mathrm{~kg}$ e divisão de $1 \mathrm{~g}$.

Foram elaborados quadros ilustrativos das porções e medidas caseiras propostas para cada refeição. Em seguida, realizou-se treinamento com a cozinheira e a auxiliar envolvidas na produção e distribuição das refeições durante uma semana, apresentando a proposta de padronização do porcionamento.

\section{Avaliação do desperdício: resto e sobras}

A avaliação dos restos e sobras foi realizada para as três refeições oferecidas pela creche (almoço, lanche da tarde e jantar), em duas etapas. Na primeira, foram pesadas as preparações produzidas, preparações distribuídas, sobras e restos durante sete dias. Após esta etapa, a intervenção foi realizada a partir da utilização do quadro ilustrativo de porcionamento. Na segunda etapa, foram pesadas preparações produzidas, preparações distribuídas, restos e sobras por quatro dias, após a medida de intervenção.

Para a obtenção do peso da preparação distribuída, foi feita a pesagem do recipiente de cada preparação depois de pronta, sendo descontado o peso do recipiente e das sobras. Os valores obtidos para cada preparação foram somados para se obter o peso da refeição distribuída. O peso do resto foi obtido mediante a raspagem do prato das crianças após o consumo de cada refeição, verificando-se a soma do conteúdo rejeitado por elas. As fórmulas utilizadas, segundo Vaz, ${ }^{15}$ estão descritas no quadro 1. 
Quadro 1. Fórmulas utilizadas para calcular os percentuais de sobras e resto-ingestão. Aracaju, SE.

\begin{tabular}{|c|}
\hline $\begin{array}{c}\text { Peso da refeição distribuída }(\mathrm{g})=\text { total produzido }(\mathrm{g}) \text { - sobras após servir } \\
\text { as refeições }(\mathrm{g})\end{array}$ \\
\hline Percentual de sobras = $\begin{array}{c}\text { sobras após servir as refeições }(\mathrm{g}) \times 100 / \text { peso das } \\
\text { refeições distribuídas }(\mathrm{g})\end{array}$ \\
\hline Percentual de resto-ingestão $=$ peso dos restos $(\mathrm{g}) \times 100 /$ peso das \\
refeições distribuídas $(\mathrm{g})$
\end{tabular}

O resto-ingestão é descrito como a relação entre o resto devolvido dos pratos e a quantidade de alimentos e preparações alimentares oferecidas, expressa em percentual. São aceitáveis, como percentual de resto-ingestão, taxas inferiores a 10\%. Quando o resultado apresenta-se acima de $10 \%$ em coletividades sadias e $20 \%$ em enfermas, pressupõe-se que os cardápios estão inadequados, por serem mal planejados ou mal executados. ${ }^{16}$

Para avaliar quantas crianças poderiam ser alimentadas com as sobras e os restos acumulados durante o período de coleta de dados, foram calculados o consumo per capita por refeição (peso das refeições distribuídas dividido pelo número de refeições).

\section{Resultados e discussão}

Avaliação de sobras e restos

O peso das sobras e restos de alimentos do almoço, lanche e jantar, oferecidos às crianças são apresentados nas tabelas 1, 2 e 3. Foram quantificados sobras e restos durante 11 dias, para se analisar o desperdício de alimentos na creche em duas etapas, (1) antes da padronização do porcionamento das refeições e (2) após a padronização do porcionamento. As trabalhadoras da unidade foram treinadas quanto à padronização do porcionamento, sendo esta etapa chamada de medida de intervenção. 
Tabela 1. Valores de restos e sobras, no almoço, antes e após a realização da medida de intervenção. Aracaju, SE.

\begin{tabular}{cccccccc}
\hline Etapa & Dia & $\begin{array}{c}\text { Quantidade } \\
\text { produzida }(\mathrm{g})\end{array}$ & $\begin{array}{c}\text { Sobras } \\
(\mathrm{g})\end{array}$ & $\begin{array}{c}\text { Quantidade } \\
\text { distribuída }(\mathrm{g})\end{array}$ & $\begin{array}{c}\text { Resto } \\
(\mathrm{g})\end{array}$ & $\begin{array}{c}\text { Resto-ingestão } \\
(\%)\end{array}$ & $\begin{array}{c}\text { Sobras } \\
(\%)\end{array}$ \\
\hline & 1 & 12735 & 6700 & 6035 & 1980 & 32,8 & 111,0 \\
$1^{*}$ & 2 & 13205 & 5830 & 7375 & 1760 & 23,9 & 79,1 \\
& 3 & 13130 & 6135 & 6995 & 2440 & 34,9 & 87,7 \\
& 4 & 11585 & 2570 & 9015 & 3740 & 41,5 & 28,5 \\
& 5 & 11860 & 2290 & 9570 & 3235 & 33,8 & 23,9 \\
& 6 & 11230 & 4200 & 7030 & 2165 & 30,8 & 59,7 \\
\hline Média & 7 & 9940 & 3025 & 6915 & 2395 & 34,6 & 43,7 \\
\hline & 1 & 9615 & 4440 & 5175 & 930 & 18,0 & 85,8 \\
& 2 & 8865 & 3845 & 5020 & 540 & 10,8 & 76,6 \\
\hline 2** & 3 & 8065 & 2360 & 5705 & 1060 & 18,6 & 41,4 \\
& 4 & 8910 & 3560 & 5350 & 800 & 15,0 & 66,5 \\
\hline Média & 8863,8 & 3551,2 & 5312,5 & 832,5 & 15,6 & 67,6 \\
\hline
\end{tabular}

*Etapa 1: pesagem das preparações do almoço, restos e sobras antes da aplicação da medida de intervenção (padronização do porcionamento).

**Etapa 2: pesagem das preparações do almoço, restos e sobras depois da aplicação da medida de intervenção (padronização do porcionamento). 
Tabela 2. Valores de restos e sobras, no lanche, antes e após a realização da medida de intervenção. Aracaju, SE.

\begin{tabular}{cccccccc}
\hline Etapa & Dia & $\begin{array}{c}\text { Quantidade } \\
\text { produzida }(\mathrm{g})\end{array}$ & $\begin{array}{c}\text { Sobras } \\
(\mathrm{g})\end{array}$ & $\begin{array}{c}\text { Quantidade } \\
\text { distribuída }(\mathrm{g})\end{array}$ & $\begin{array}{c}\text { Resto } \\
(\mathrm{g})\end{array}$ & $\begin{array}{c}\text { Resto-ingestão } \\
(\%)\end{array}$ & $\begin{array}{c}\text { Sobras } \\
(\%)\end{array}$ \\
\hline & 1 & 1960 & 0 & 1960 & 295 & 15,1 & 0,0 \\
$1^{*}$ & 2 & 7150 & 400 & 6750 & 1350 & 20,0 & 5,9 \\
& 3 & 6635 & 1360 & 5275 & 1185 & 22,5 & 25,8 \\
& 5 & 5395 & 85 & 5310 & 1565 & 29,5 & 1,6 \\
& 5 & 5530 & 0 & 5530 & 830 & 15,0 & 0,0 \\
& 7 & 4690 & 730 & 3960 & 1100 & 27,8 & 18,4 \\
\hline Média & 3780 & 750 & 3030 & 445 & 14,7 & 24,8 \\
\hline & 1 & 4870 & 1225 & 3645 & 415 & 11,4 & 33,6 \\
& 2 & 2230 & 45 & 2185 & 300 & 13,7 & 2,1 \\
\hline 2** & 3 & 4670 & 265 & 4405 & 885 & 20,1 & 6,0 \\
& 4 & 3300 & 550 & 2750 & 295 & 10,7 & 20,0 \\
\hline Média & 3767,5 & 521,3 & 3246,3 & 473,8 & 13,9 & 15,4 \\
\hline
\end{tabular}

*Etapa 1: pesagem das preparações do lanche, restos e sobras antes da aplicação da medida de intervenção (padronização do porcionamento).

**Etapa 2: pesagem das preparações do lanche, restos e sobras depois da aplicação da medida de intervenção (padronização do porcionamento). 
Tabela 3. Valores de restos e sobras, no jantar, antes e após a realização da medida de intervenção. Aracaju, SE.

\begin{tabular}{cccccccc}
\hline Etapa & Dia & $\begin{array}{c}\text { Quantidade } \\
\text { produzida }(\mathrm{g})\end{array}$ & $\begin{array}{c}\text { Sobras } \\
(\mathrm{g})\end{array}$ & $\begin{array}{c}\text { Quantidade } \\
\text { distribuída }(\mathrm{g})\end{array}$ & $\begin{array}{c}\text { Resto } \\
(\mathrm{g})\end{array}$ & $\begin{array}{c}\text { Resto-ingestão } \\
(\%)\end{array}$ & $\begin{array}{c}\text { Sobras } \\
(\%)\end{array}$ \\
\hline & 1 & 3195 & 1235 & 1960 & 660 & 33,7 & 63,0 \\
$1^{*}$ & 2 & 4930 & 1750 & 3180 & 2030 & 63,8 & 55,0 \\
& 3 & 7005 & 1490 & 5515 & 1555 & 28,2 & 27,0 \\
& 4 & 5550 & 1585 & 3965 & 1850 & 46,7 & 40,0 \\
& 5 & 3665 & 310 & 3355 & 860 & 25,6 & 9,2 \\
& 6 & 5415 & 1705 & 3710 & 375 & 10,1 & 46,0 \\
\hline Média & 7 & 3980 & 1205 & 2775 & 1190 & 42,9 & 43,4 \\
\hline & 1 & 3820 & 1325,7 & 3494,3 & 1217 & 35,9 & 40,5 \\
\hline 2** & 2 & 6745 & 3870 & 2875 & 360 & 12,5 & 134,6 \\
& 3 & 6055 & 2150 & 3905 & 1110 & 28,4 & 55,1 \\
\hline Média & 4 & 4370 & 400 & 3970 & 225 & 5,7 & 10,1 \\
\hline
\end{tabular}

*Etapa 1: pesagem das preparações do jantar, restos e sobras antes da aplicação da medida de intervenção (padronização do porcionamento).

**Etapa 2: pesagem das preparações do jantar, restos e sobras depois da aplicação da medida de intervenção (padronização do porcionamento). 
O cardápio nas etapas 1 e 2 não foram iguais, uma vez que não foi possível interferir no seu planejamento. Entretanto, não há grande variedade de preparações no cardápio em geral e muitas das preparações se repetiram na etapa 2.

Observa-se, na etapa 1, alto percentual de resto-ingestão e de sobras nas grandes refeições os maiores percentuais de resto-ingestão e sobras chegaram a $64 \%$ e $111 \%$, respectivamente. Os dados da literatura não oferecem parâmetros de resto-ingestão para crianças, mas para adultos, consideram-se percentuais de resto-ingestão aceitáveis quando estes se encontram abaixo de $10 \%{ }^{16}$

Nota-se que, em alguns dias, o percentual de sobras ultrapassa $100 \%$, porque o cálculo do percentual de sobras é obtido mediante a razão do peso das sobras e o peso das refeições que foram distribuídas. Como a sobra apresentou-se maior que a quantidade distribuída em alguns dias, a porcentagem ultrapassou $100 \%$. Isso mostra que, possivelmente, havia grande desequilíbrio entre a demanda de refeições e a quantidade de alimentos produzidos.

Soares et al., ${ }^{17}$ estudando as sobras em oito unidades de alimentação e nutrição de uma empresa siderúrgica durante cinco meses, encontraram até $1.213 \mathrm{Kg}$ de alimentos desperdiçados mensalmente, o que correspondeu a $3 \%$ dos gastos mensais com alimentos. As autoras ressaltaram não só a perda financeira resultante do desperdício, mas também o impacto socioambiental da geração excessiva de resíduos.

Ao analisar as tabelas 1, 2 e 3, observa-se que a refeição em que houve maior desperdício foi o almoço, que apresentou altos percentuais de sobras. Em média, mais da metade do que foi produzido foi descartado. Por outro lado, o lanche foi a refeição que apresentou menor desperdício.

Na etapa 2, após a aplicação do treinamento sobre porcionamento empregando medidas padronizadas, verificou-se que o percentual médio de resto-ingestão nas grandes refeições diminuiu à metade quando comparado à etapa 1. Possivelmente, as quantidades antes oferecidas às crianças não estavam adequadas, fato que poderia estar ocasionando os altos índices de resto-ingestão encontrados. Entretanto, o percentual médio de sobras aumentou nas refeições na etapa 2, o que se justifica porque o tamanho da porção definida para as preparações foi reduzido, mas a princípio a quantidade total produzida não foi alterada; logo, a quantidade de sobras aumentou. Ao ser constatado, esse fato foi repassado à nutricionista responsável pela unidade, para que pudesse ser feito o ajuste no momento do planejamento, desde as compras até a produção das refeições. Observou-se que havia dificuldade para o nutricionista realizar o acompanhamento sistemático da produção e distribuição das refeições na creche, uma vez que era responsável também pela produção das refeições em outras unidades, de maior porte, da mesma instituição, para atendimento 
de trabalhadores e estudantes. Ressalta-se a importância de acompanhar diariamente o volume de sobras como informação importante para planejar e elaborar quantidades suficientes de cada preparação, a fim de evitar excessos de produção e geração de resíduos desnecessários.

Durante a primeira etapa, os valores de sobras e restos acumulados somaram $43.335 \mathrm{~g}$ e $33.005 \mathrm{~g}$, respectivamente. Esse total alimentaria, durante os sete dias, 323 crianças; 183 crianças com as sobras acumuladas e 140 crianças com os restos acumulados, considerando-se o porcionamento proposto.

Em trabalho realizado por Augustini et al. ${ }^{18}$ em uma unidade de alimentação e nutrição (UAN) de uma empresa metalúrgica, foram encontrados baixos percentuais de sobras no almoço e no jantar (entre 5 e 13\%), diferentemente do resultado do presente estudo. Com relação ao índice de resto-ingestão, os percentuais encontrados por Augustini et al., ${ }^{18} \mathrm{em}$ geral menores que 10\%, foram mais baixos do que os percentuais de resto-ingestão observados na creche em estudo.

Conforme Hirschbruch, ${ }^{19}$ numa UAN o desperdício pode envolver as sobras e restos de alimentos e preparações prontas e pode ser influenciado por uma série de fatores: planejamento inadequado do número de refeições a serem produzidas, preferências alimentares, falta de treinamento dos funcionários na produção e no porcionamento.

Durante o desenvolvimento deste trabalho, foram identificados alguns fatores que podem ser relacionados aos elevados percentuais de sobras encontrados, a saber: falta de fichas técnicas, o que gerou a dificuldade de estabelecimento de per capitas ajustados às crianças; o receio, por parte das cozinheiras, de que a quantidade produzida não atendesse à demanda, já que o número diário de crianças presentes a cada dia não era informado com antecedência.

Conforme comentado anteriormente, à época do estudo a disponibilidade de tempo do nutricionista para a creche era bastante limitada, o que gerou implicações no acompanhamento técnico da produção. Entretanto, esta situação foi alterada com a contratação de novos nutricionistas pela instituição. Além disso, destaca-se o fato de que as funcionárias da creche trabalhavam anteriormente com produção de refeições em restaurante para população adulta. Isso pode ser um dos fatores que influenciaram a grande quantidade de alimentos preparada, bem como a quantidade de alimentos porcionada nos pratos das crianças na etapa 1.

Com relação aos elevados índices de restos na etapa 1 , foram observados outros fatores que poderiam estar influenciando negativamente a ingestão das refeições, como o fato de os alimentos não serem amassados o suficiente. Durante o estudo, observou-se que quando algumas preparações eram oferecidas pouco amassadas, as crianças descartavam o alimento do prato com as mãos e não o ingeriam. O Ministério da Saúde, ${ }^{1}$ orienta que para ofertar a alimentação complementar, deve-se 
começar com consistência pastosa (papas/purês) e, gradativamente, aumentar a consistência até se chegar à alimentação da família. Vitolo ${ }^{20}$ também ressalta que as frutas devem ser amassadas e a papa salgada deve ter os alimentos bem cozidos e amassados para o primeiro ano de vida. Por isso, faz-se necessário adequar a consistência do alimento à idade da criança para melhor adesão à alimentação complementar.

Outro fator identificado, específico para o jantar, é o fato de que algumas crianças deixam a creche antes de o jantar ser servido. Por isso, em alguns dias, pratos que não foram abertos, foram pesados como "resto". A falta de padronização no porcionamento também se insere como um fator para os altos índices de resto na etapa 1, uma vez que se observou que as quantidades porcionadas nos pratos eram muito grandes, considerando a faixa etária das crianças.

O pequeno intervalo entre o lanche e jantar também pode ter favorecido o alto percentual de restos no jantar. Os intervalos entre as refeições e os lanches estão positivamente relacionados com o tamanho das refeições - ou seja, quanto maior o intervalo, maior a quantidade de alimentos ingeridos no momento da refeição. ${ }^{20} \mathrm{O}$ poder de saciedade do alimento consumido determinaria biologicamente o próximo momento de se alimentar. O apetite inconstante, em geral, mais relacionado aos pré-escolares, também pode ser um fator responsável pelos altos índices de restoingestão na etapa 1. É comum a criança entre um e seis anos apresentar inapetência alimentar, que se associa à diminuição da velocidade do crescimento e também aos fatores comportamentais, quando a criança deixa de comer para chamar atenção, entre outros motivos. ${ }^{20}$

Quanto ao uso dos percentuais de resto-ingestão para avaliar indiretamente a aceitabilidade das refeições, cabem algumas considerações, quando a população estudada se trata de crianças tão pequenas. O Ministério da Educação recomenda, para a aplicação do teste de aceitabilidade, as metodologias de "Resto-ingestão" ou "Escala Hedônica", observando-se parâmetros técnicos, científicos e sensoriais reconhecidos. ${ }^{13}$ Devido à faixa etária da população deste estudo, o restoingestão, então, seria a metodologia mais adequada para avaliar a aceitabilidade da alimentação. Em contrapartida, o manual para aplicação dos testes de aceitabilidade no Programa Nacional de Alimentação Escolar (PNAE), elaborado por UNIFESP e UnB,${ }^{21}$ não recomenda o teste de aceitabilidade para a população de creches: "[...] com relação às creches, é sabido que, a partir dos seis meses de idade, deve ocorrer a introdução de novos alimentos no padrão alimentar da criança, e que essa introdução deverá ser feita de forma lenta e gradual, pois a criança tende a rejeitar as primeiras ofertas. Ademais, recomenda-se, nesse caso, de oito a dez exposições a um novo alimento para que ele seja aceito pelo infante sem necessariamente ter uma preocupação constante de conciliação com a aceitabilidade da criança. Com esse indicativo, fica o teste de aceitabilidade invalidado para a clientela de creches, pois o rejeite neste caso pode não fazer correlações de aceitação ou de preferência." 
Sendo assim, os valores de resto não foram usados para avaliar a aceitabilidade, e sim para auxiliar na padronização do porcionamento das refeições.

\section{Padronização do porcionamento}

O tamanho das porções e medidas caseiras foi padronizado para cada uma das turmas: crianças de oito meses a um ano e cinco meses de idade (turma 1) e crianças de um ano e seis meses a dois anos (turma 2). A recomendação energética média para a turma 1 foi de 902 kcal, e para a turma 2 foi de 1214 kcal. Para atender às necessidades calóricas das crianças, utilizaram-se $60 \%$ do valor da recomendação calórica diária, tendo em vista que a creche oferece três refeições. Logo, para a turma 1, 60\% corresponderam a $541 \mathrm{kcal}$, e para a turma 2, esse valor correspondeu a $728 \mathrm{kcal}$.

A tabela 4 apresenta a padronização das porções, medidas caseiras e o respectivo conteúdo energético para preparações do almoço, lanche da tarde e jantar. A padronização das medidas caseiras foi baseada em três dias que apresentavam diferentes preparações frequentemente utilizadas na creche. A adequação do valor calórico diário à proposta de ofertar $60 \%$ da recomendação média de energia foi de $106 \%, 95 \%$ e $71 \%$ nos três dias, respectivamente, para a turma 1. Para a turma 2, a adequação energética foi de 91\%, 92\% e 63\% nos três dias, respectivamente. 


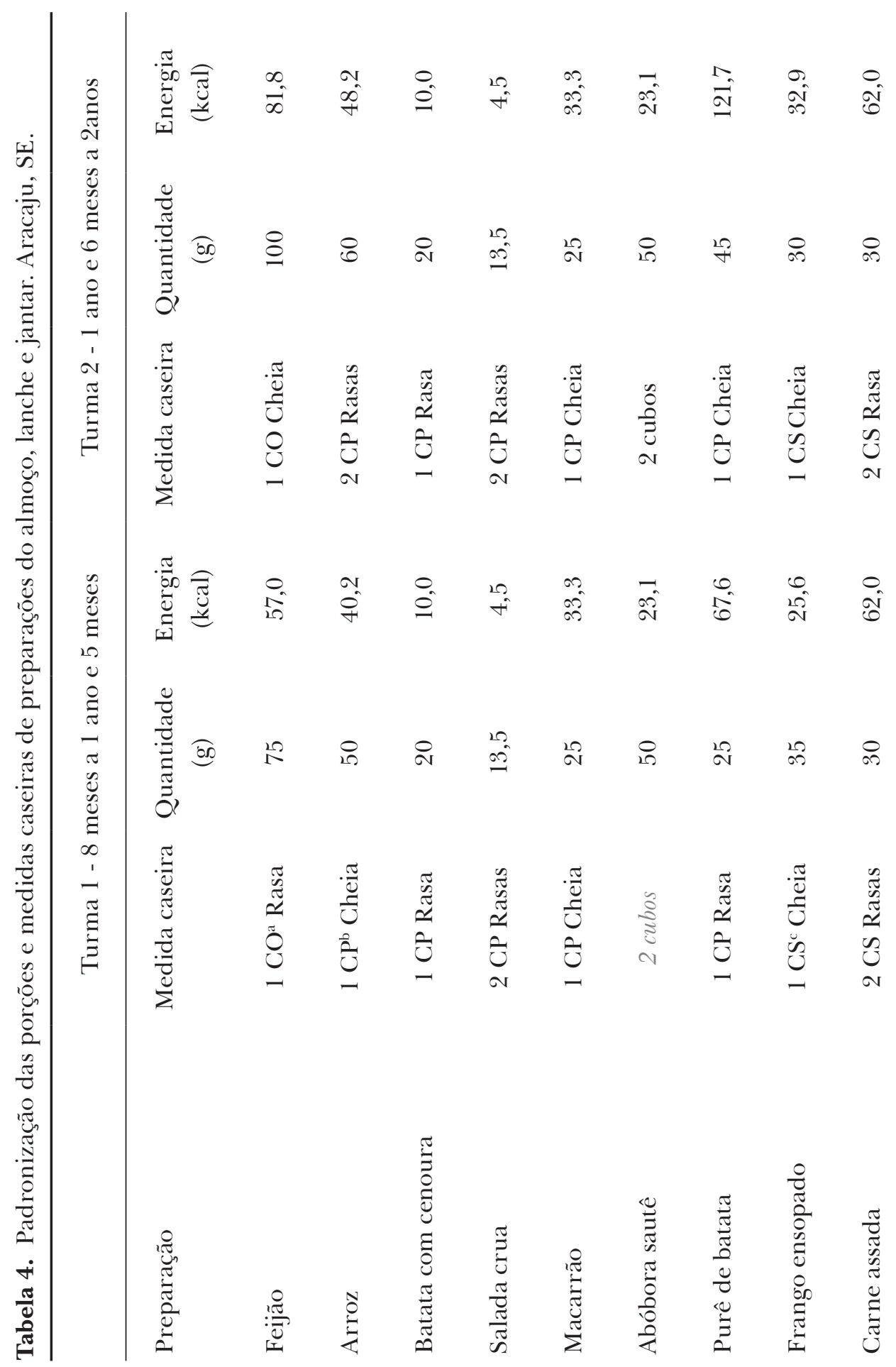




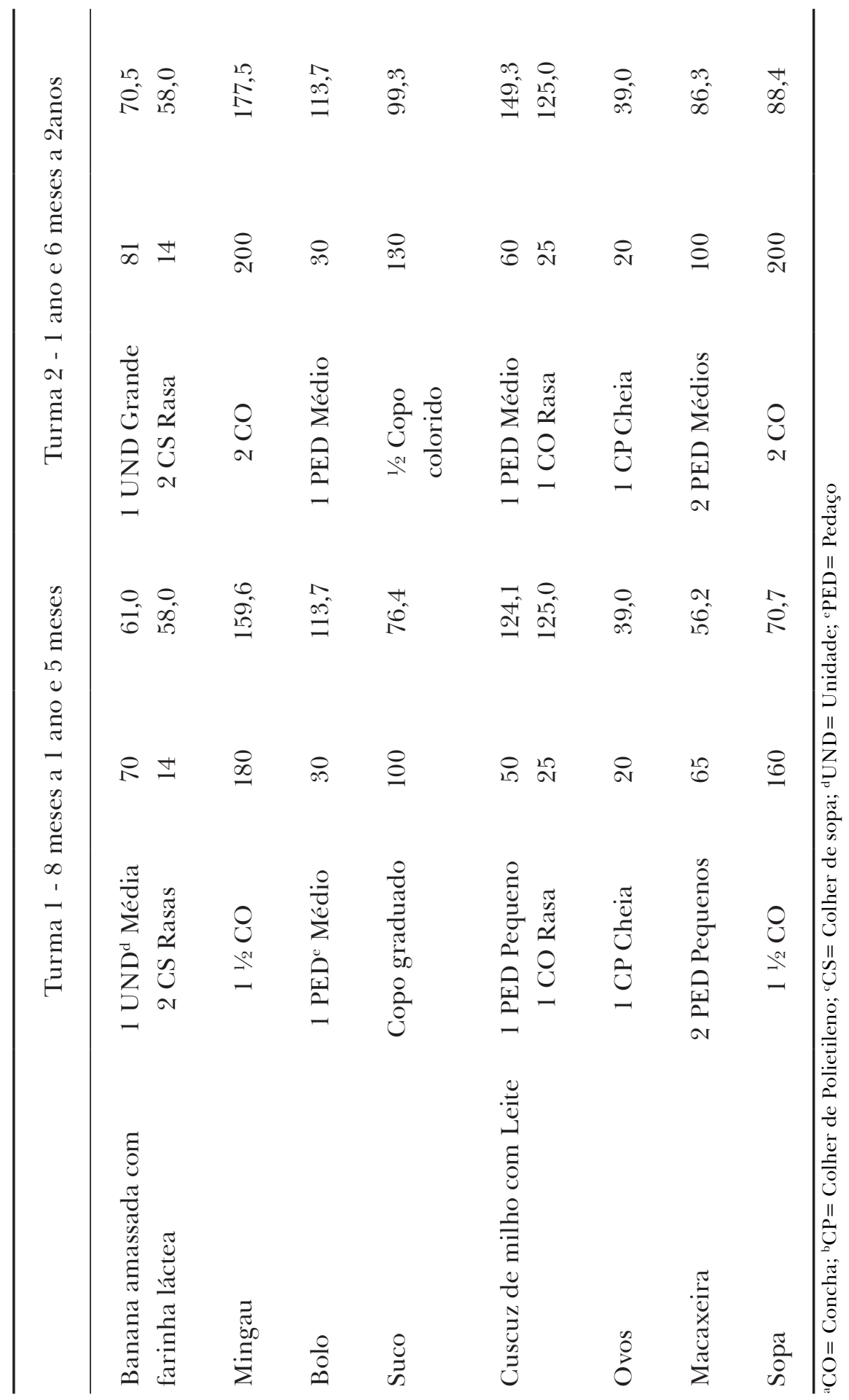


O cardápio do terceiro dia incluía algumas preparações de baixa densidade calórica, como abóbora sauté no almoço e sopa de legumes no jantar. Por isso, possivelmente, a adequação do valor calórico tenha sido tão baixa nesse dia em ambas as turmas. Enfatiza-se o fato de a sopa possuir naturalmente baixo teor calórico e ser ofertada no jantar, que é uma grande refeição e deveria contribuir com maior percentual para o atendimento das necessidades calóricas diárias.

Foram encontradas algumas dificuldades para realizar a padronização de medidas caseiras de forma a adequar a oferta de energia. Ao calcular o valor calórico das preparações, verificouse que algumas apresentavam baixa densidade energética. Isso dificultou o estabelecimento da porção, porque o valor calórico de algumas preparações era baixo, logo seria necessário aumentar o tamanho da porção para atender à meta de ofertar $60 \%$ da recomendação. Entretanto, um fator que também deve ser observado para padronizar o tamanho da porção para crianças nessa faixa etária é o pequeno volume gástrico da criança, que não suporta grandes quantidades.

A revisão do cardápio, procurando minimizar a presença de preparações de baixa densidade energética (abaixo de $0,7 \mathrm{Kcal} / \mathrm{g}^{1}$ ), é uma medida importante para adequar a oferta de energia na creche. Apesar da redução, os restos alimentares das crianças ainda são consideráveis, o que, portanto, reduz ainda mais a quantidade de energia consumida diariamente. Sendo assim, a atenção quanto à variedade do cardápio, textura e densidade energética das preparações assume papel essencial no fornecimento de refeições na creche.

Durante o período de acompanhamento do preparo de alimentos, constatou-se que foi utilizada pequena quantidade de óleo nas preparações. Em alguns casos, a baixa densidade energética de algumas preparações está relacionada a esse fato. Não se pretende dizer que se deve aumentar a oferta de óleo indiscriminadamente, mas sabe-se que, além da importância energética, os óleos são fontes de nutrientes importantes, como ácidos graxos essenciais, e têm papel importante na absorção de vitaminas A, D, E e K. Sendo assim, eles devem ser usados no preparo dos alimentos.

Outra dificuldade observada foi o curto período de tempo entre o lanche da tarde e o jantar (2 horas), fator que limitou a padronização de tamanhos maiores para as porções. Porções maiores no lanche poderiam resultar em menor aceitação do jantar.

Observa-se, na tabela 4, que em algumas preparações o tamanho da porção foi padronizado igualmente para as duas turmas. Optou-se por utilizar a mesma medida para bolos, farinha láctea e leite, para facilitar o porcionamento executado pelas trabalhadoras. No caso de saladas e macarrão, mantiveram-se as medidas já empregadas na creche, pois foram consideradas adequadas do ponto de vista quantitativo e energético.

Com relação à porção de carne, optou-se por aumentar de uma colher de sopa rasa para uma colher de sopa cheia na turma 1, para melhor adequar o valor calórico da refeição. Além disso, esses alimentos são fontes importantes de proteínas e micronutrientes, e acredita-se que a única 
oportunidade de a criança ingerir alimentos como carne e ovo, de segunda a sexta-feira, é na creche, já que é lá que ela realiza duas das principais refeições do dia (almoço e jantar). Em dias úteis, as refeições que as crianças recebem em casa, em geral, são à base de leite.

Segundo Vitolo, ${ }^{20}$ ao introduzir a alimentação complementar, é importante que já haja a inclusão da carne, para garantir o ferro de boa biodisponibilidade. A demora na introdução de alimentos com ferro de boa biodisponibilidade pode esgotar as reservas de ferro da criança e colocá-la em risco para o quadro de anemias.

O suco teve a quantidade padronizada em $100 \mathrm{ml}$ para a turma 1 e $130 \mathrm{ml}$ para a turma 2, como complemento do lanche da tarde. Observou-se baixa frequência de oferta de frutas nas refeições, por isso a oferta de sucos naturais foi mantida, como oportunidade para oferecer uma porção do grupo das frutas. Apesar de ser uma preparação com baixa densidade energética, a presença de vitaminas e minerais, importantes para o crescimento saudável da criança, deve ser levada em consideração neste grupo de alimentos.

De acordo com Longo-Silva et al., ${ }^{7}$ que realizaram estudo em 16 creches, os problemas encontrados quanto à ingestão calórica insuficiente podem estar relacionados a falhas no processo de produção, porcionamento e distribuição das refeições, sendo influenciados não só pelo tamanho das porções, mas também pelo número de refeições diárias e pela variedade e densidade energética dos alimentos servidos. Os autores admitem a dificuldade de garantir a ingestão energética diária adequada e que, embora os cardápios sejam planejados por nutricionistas, a alimentação das crianças mostrou-se insuficiente, o que reforça a necessidade de ações de educação, especialmente voltadas para os trabalhadores que porcionam as refeições e alimentam as crianças.

Para apresentação da padronização do porcionamento, foram elaborados três quadros ilustrativos (para o almoço, para o lanche e para o jantar), que apresentavam a quantidade em medida caseira e a respectiva foto da porção adequada para cada preparação (figura 1). Proposta semelhante foi realizada por Goulart et al., ${ }^{22}$ com a criação de um guia ilustrativo de medidas caseiras padronizadas das refeições de almoço e jantar em ambiente hospitalar, com o objetivo de auxiliar no porcionamento. Os autores concluíram que a utilização do guia foi uma medida eficiente para melhorar a qualidade no porcionamento dos alimentos e padronização das dietas, ressaltando ainda a importância da realização de treinamento com os funcionários que participam do processo. 


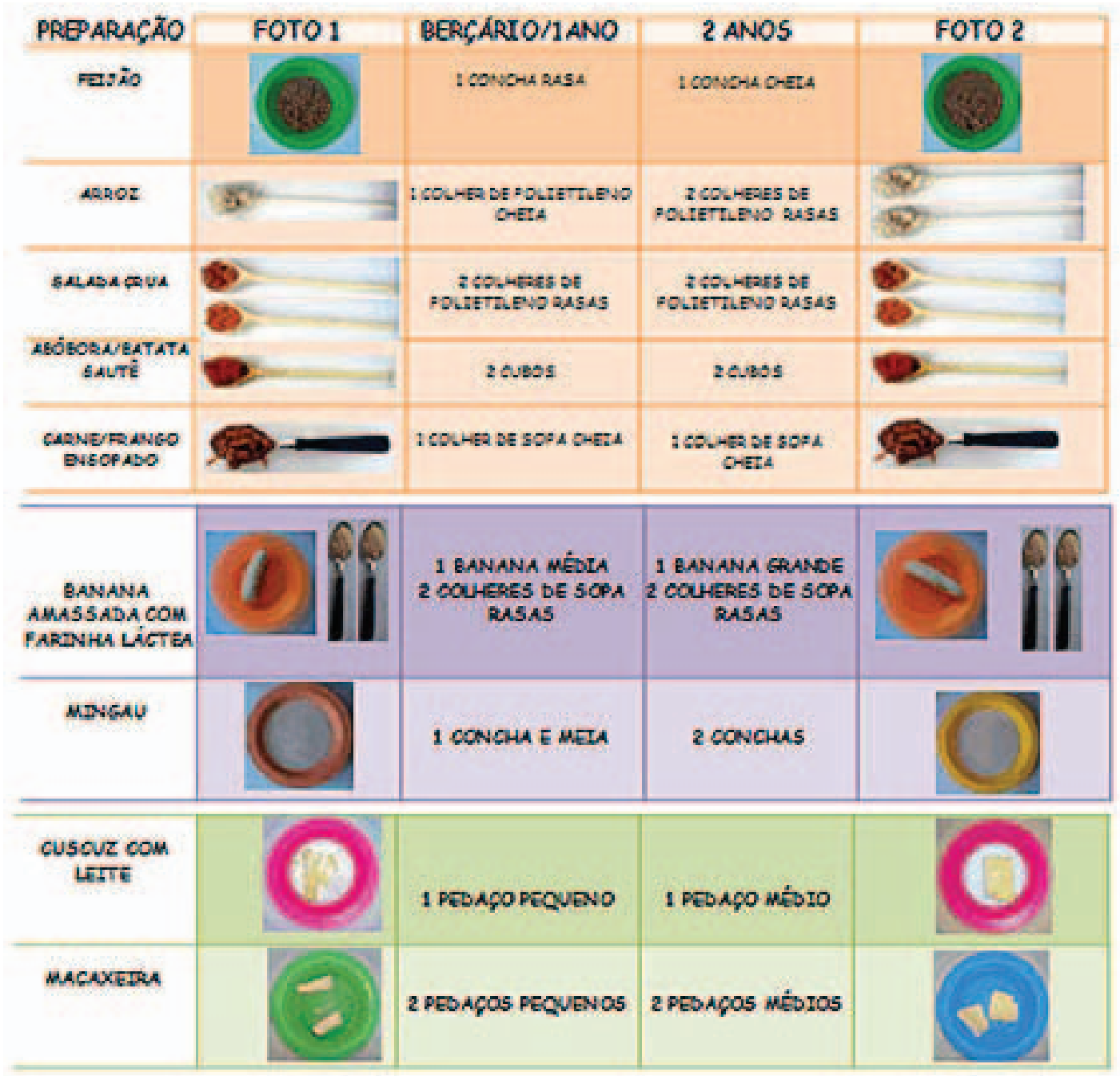

Figura 1. Imagem parcial dos quadros de porções de alimentos servidos no almoço (cor laranja), lanche (cor roxa) e jantar (cor verde) 
No presente estudo, o treinamento quanto à utilização dos quadros foi conduzido durante uma semana, junto às trabalhadoras, discutindo-se a forma de utilizá-lo, qual a finalidade e a importância do instrumento no dia a dia das cozinheiras. A proposta foi estabelecer com as trabalhadoras uma relação dialógica, a fim que a aprendizagem não fosse baseada na imposição, mas na ação motivada.

Conforme Freire, ${ }^{9}$ a verdadeira comunicação se dá por meio do diálogo em que educador e educando são ativos e estão no mesmo nível. Assim, procurou se "aproveitar os conhecimentos prévios adquiridos ao longo da vida do sujeito, a fim de valorizar o aprendizado, transformando o aprendiz de objeto a sujeito da educação”, conforme o modelo andragógico. ${ }^{23}$

Para elaborar os quadros do presente estudo, foram considerados os tamanhos das porções estabelecidas com base na oferta energética desejada e nas orientações da literatura para crianças na faixa etária de sete meses a três anos.

Para facilitar o entendimento das cozinheiras, as medidas caseiras foram descritas com base em utensílios rotineiramente usados na unidade e na discussão sobre o tamanho das porções entre uma das autoras do trabalho as cozinheiras. A quantidade de cada porção foi pesada e a escolha da medida caseira adequada foi discutida com as cozinheiras. De acordo com as respostas e discussões, as medidas caseiras foram sendo definidas de forma a facilitar o trabalho das cozinheiras, adequando o tamanho das porções anteriormente propostas, mas procurando atender à necessidade energética das crianças e evitar o desperdício de alimentos.

Após a discussão dos quadros com as cozinheiras, foram realizados ajustes baseados nas observações feitas pelas trabalhadoras, como por exemplo: a medida caseira da banana, proposta pelas pesquisadoras, foi identificada pela cozinheira como de difícil interpretação, pois a mesma alegou que era difícil diferenciar uma banana média de uma banana grande. Foi sugerido pela própria cozinheira que a medida caseira fosse descrita não em dimensão, mas em valor unitário, por exemplo: $1 / 2$ banana, 1 banana e 1 e $1 / 2$ banana.

O papel dos trabalhadores neste ambiente é fundamental para os resultados, pois atua como o ponto-chave para que a padronização seja concretizada de fato. O envolvimento das cozinheiras na seleção das medidas caseiras e discussão do quadro ilustrativo para o porcionamento mostrou-se fundamental para atingir os resultados. A educação alimentar e nutricional também é fundamental para que isso ocorra, uma vez que se discutem a importância e utilidade da padronização de medidas caseiras em um ambiente produtor de refeições. Assim, as trabalhadoras puderam compreender a importância prática do assunto, reconhecendo a situação vivida no seu local de trabalho e podendo agir para sua transformação, tanto em relação à alimentação de cada criança, quanto em relação ao desperdício para a creche enquanto instituição. 
O planejamento do cardápio é uma etapa fundamental para a oferta de uma alimentação saudável. Entretanto, é necessário que o cardápio seja executado conforme planejado e que o porcionamento ocorra de maneira adequada. Somente assim é possível garantir que a alimentação oferecida na creche irá cumprir seu papel essencial no desenvolvimento das crianças.

\section{Conclusão}

Foram observados altos índices de resto-ingestão e desperdício antes da padronização do porcionamento. Após a introdução dessa medida, os percentuais médios de resto-ingestão reduziram-se quase à metade. Os dados da etapa 1 demonstram a dimensão do desperdício, uma vez que os restos e sobras acumulados alimentariam 30 crianças por dia.

A adequação da oferta energética foi parcialmente alcançada a partir da padronização do porcionamento, mas observou-se que existem outros fatores determinantes para que as recomendações energéticas sejam atingidas, como por exemplo, o planejamento do cardápio, de forma a não concentrar preparações de baixa densidade energética em um mesmo dia. Observou-se ainda que as peculiaridades da faixa etária tratada no estudo devem ser levadas em consideração para a oferta de uma alimentação adequada, como por exemplo, a consistência das preparações e intervalo de tempo entre as refeições. A experiência de treinamento das trabalhadoras mostrou-se muito enriquecedora e crucial para a proposta.

Durante o estudo, foi observado que os percentuais de sobras aumentaram na etapa 2 devido à redução do tamanho da porção. Sugere-se que sejam realizados ajustes, como a readequação do pedido de compras e a implantação de fichas técnicas, para minimizar o desperdício alimentar.

Embora este trabalho tenha envolvido apenas uma creche, algumas observações podem ser aproveitadas em outras situações, cabendo a adaptação necessária a cada realidade. Ainda que se tenha observado que o porcionamento sozinho não resolve as questões de adequação da oferta energética e controle do desperdício, sua padronização é uma ferramenta que merece atenção, dado seu impacto significativo nessas questões.

Apesar das limitações do presente estudo, foi possível observar que a padronização do porcionamento é essencial para garantir a oferta adequada de refeições para atender às necessidades das crianças e que tal padronização pode contribuir para a redução do desperdício de alimentos, o que tem repercussões no volume de resíduos produzidos e nos custos da unidade. 


\section{Referências}

1. Organização Pan-Americana da Saúde. Guia alimentar para crianças menores de dois anos. Brasília: Ministério da Saúde; 2002.

2. Organização Mundial da Saúde, Organização Pan-Americana da Saúde. Normas alimentares para crianças brasileiras menores de dois anos [monografia na Internet]. [S.l. : s.n.]; 1997. [Acesso em: 2011 jul 10] Disponível em: <http://www.opas.org.br/sistema/arquivos/bases.pdf>.

3. Bruschini C. O trabalho da mulher nas décadas recentes. Rev Estud Fem., 1994;(n.esp.):179-99.

4. Seabra KC, Moura MLS. Alimentação no ambiente de creche como contexto de interação nos primeiros dois anos de um bebê. Psicol estud. 2005;10(1):77-86.

5. Schilling M. Qualidade em nutrição: método de melhorias contínuas ao alcance de indivíduos e coletividades. São Paulo: Varela; 1995.

6. BRASIL. Ministérios do Desenvolvimento Social e Combate à Fome. Marco de referência de educação alimentar e nutricional para as políticas públicas [monografia na Internet]. [S.l.: s.n.]; 2012. [Acesso em: 2013 jan 25] Disponível em: <http://fs.unb.br/opsan/consulta-publica/pdf/Marco_referencia_ Textocompleto.pdf $>$.

7. Longo-Silva G, Toloni MHA, Goulart RMM, Taddei JAAC. Evaluation of food consumption at public day care centers in São Paulo, Brazil. Rev paul pediatr. 2012;30(1):35-41.

8. Vargas SV. Padronização de medidas caseiras como ferramenta à dietoterapia. Vittalle. 2007;19(1):29-34.

9. Freire P. Educação e mudança. 24a ed. Rio de Janeiro: Paz e Terra; 2001.

10. BRASIL. Casa Civil. Lei n 12.305 de 02 de agosto de 2010. Institui a Política Nacional de Resíduos Sólidos; altera a Lei n 9.605, de 12 de fevereiro de 1998; e dá outras providências. Diário Oficial da União, 2010 ago. 3.

11. National Research Council (US). Recommended dietary allowances. 10th ed. Washington, DC: National Academy Press; 1989.

12. Yates AA, Schlicker SA, Suitor CWCW. Dietary reference intakes: the new basis for recommendations for calcium and related nutrients, B vitamins, and choline. J Am Diet Assoc.1998;98(6).

13. BRASIL. Ministério da Educação. Fundo Nacional de Desenvolvimento da Educação - Conselho Deliberativo. Resolução/CD/FNDE Nº 38, de 16 de julho de 2009.Dispõe sobre o atendimento da alimentação escolar aos alunos da educação básica no Programa Nacional de Alimentação Escolar - PNAE. Diário Oficial da União, 2009 jul.17.

14. Universidade Estadual de Campinas. Núcleo de Estudos e Pesquisas em Alimentação. Tabela brasileira de composição de alimentos: versão II. 2a ed. Campinas:Unicamp; 2006.

15. Vaz CS. Restaurantes: controlando custos e aumentando lucros. Brasília: Metha; 2006.

16. Castro MDAS, Oliveira LF, Passamani L. Resto-ingesta e aceitação de refeições em uma unidade de alimentação e nutrição. Hig aliment. 2003;(114-5):24-9. 
17. Soares ICC, Silva ER, Priore SE, Ribeiro RCL, Pereira MMLS, Pinheiro-Sant'ana HM. Quantificação e análise do custo da sobra limpa em unidades de alimentação e nutrição de uma empresa de grande porte. Rev Nutr. 2011;24(4):593-604.

18. Augustini VCM, Kishimoto P, Tescaro, TC, Almeida FQA. Avaliação do índice de resto-ingestão e sobras em Unidade de Alimentação e Nutrição (UAN) de uma empresa metalúrgica na cidade de Piracicaba/SP. Simbio-Logias. 2008; 1(1).

19. Hirschbruch MD. Unidades de Alimentação e Nutrição: desperdício de alimentos x qualidade da produção. Hig Aliment. 1998;12(55):12-14.

20. Vitolo MR. Nutrição: da gestação ao envelhecimento. Rio de Janeiro: Rubio; 2008.

21. Universidade Federal de São Paulo, Universidade de Brasília. Manual para aplicação dos testes de aceitabilidade no Programa Nacional de Alimentação Escolar - PNAE. Brasília: UnB; 2010.

22. Goulart G, Nascimento M, Alencar MLA, Sousa AA, Kuntz MGF. Construção de um guia ilustrativo de medidas caseiras padronizadas para o porcionamento de componentes do cardápio do SND/HU/ UFSC. Nutr pauta. 2010;18(100):58-62.

23. Carvalho JA, Carvalho MP, Barreto MAM, Alves FA. Andragogia: considerações sobre a aprendizagem do adulto. REMPEC. 2010;3(1):78-90. 
